visit the Canadian settlement Churchill on Hudson Bay, to investigate the cosmic-ray intensity at a height of twenty miles. A fourfold coincidence arrangement of Geiger counters carried aloft on free balloons will be used, and the observations, together with data for the almospheric pressure, and the temperature within the apparatus, will be transmitted by radio and recorded on moving tape on the ground. Previous height measurements of cosmic rays up to $30,000 \mathrm{ft}$. were made with specially equipped B-29 aircraft. Churchill is chosen as the venue of the expedition because of its high geomagnetic latitude $\left(69^{\circ}\right)$. It is hoped to determine whether at $100,000 \mathrm{ft}$. height the cosmic-ray intensity continues to increase with geomagnetic latitude; if not, one interpretation would be that the cut-off is caused by the action of a solar magnetic field. Canadian meteorologists stationed at Churchill will take part in the work. It may be hoped that it has been possible to arrange to use these flights for the determination of the winds at $100,000 \mathrm{ft}$., on which our information is still very scanty. Prevehtion of Corrosion by Vapour-phase In-
hibitors

Advances within recent years in corrosionpreventive packging haye included the use of 'vapour-phase inl ibitors' These are organic compounds, solid at Ardinffy temperatures, the vapour of which, by sur forming the metal article within a closed dntain f foduces on the surface an invisible protectve film. Corrosion of the article is thereby prenented, even in the presence of condensed moisture, actual contact with the solid inhibitor being unnecessary. Much work in this field has been carried out by the oil industry, and a product stated to have a high degree of efficiency has recently been announced by Shell Chemicals, Ltd., 112 Strand, London, W.C.2. The substance, 'Shell V.P.I. 260', is described as a white crystalline compound, odourless and non-toxic; according to the patent specification it is the nitrite salt of an organic nitrogen base. Applicable in powder form or in solution, the most convenient method is stated to be by use of coated wrapping materials. The article is enclosed in the impregnated wrap, and the protective vapour permeates to every recess. Hermetic sealing is not necessary, but longer life is afforded by a further wrap in a waxed or laminated paper; impregnated heavy cloths can be used to protect equipment or materials in process. Steel appears to be particularly amenable to rust-prevention by traces of the inhibitor even when moisture condenses. Other metals protected by 'V.P.I.260' are stated to be aluminium, duraluzin, cast-iron and chromium plate.

Forest Research Institute and Colleges, Dehra Dun

To those who have known of and followed the history of the Fores Research Institute at Dehra Dun sinceits first iflephion in India by Lord Curzon and Sir Farqlef Wilmot in 1906, it may appear cysigy that $t$ president of the Institute and Cl. ged should have considered it necessary to issue a Damphlet on its scope and functions. The notable part the Institute has played in forest research and the remarkable results achieved during the two world wars in making India independent of many types of imports have been noted in Nature from time to time. The British forest officers who started and brought the Institute to its present fine position in the world of forest research have left a great legacy in the hands of their Indian successors. The present publication is doubtless intended chiefly for the new India and Pakistan, and for that purpose it may be hoped that it will be widely read. Those interested in forestry research in different parts of the world will follow with keen interest the future progress made by the Dehra Dun Institute under its president, Mr. C. R. Ranganathan, to whom all its well-wishers will wish every success.

\section{Journal of Research and Development : British Cast Iron Research Association}

From August onwards the Journal of Research and Development jssued by the British Cast Iron Research Association will cease to be a confidential publication and will be generally available to non-members of the Association on subseription terms. This decision has been based chiefly on the large increase in mombership of the Association; it is now felt that it is neither practicable nor desirable to maintain the confidential status of a journal which is so widely circulated. The Journal contains reports of com. plete investigations conducted by the research and development staffs of the Association, together with papers presented at Association conferences, and a wide variety of subjects is dealt with. The Journal is published in alternate months, six issues a year, and the annual subscription is $£ 2$ or eight dollars, post paid. The first number of Volume 3 will appear in August; subscriptions can be sent through booksellers or direct to the British Cast Iron Research Association, Alvechurch, Birmingham.

Aeolotrophy and Seispology
THE mathematicaffroblem of the seismological
implications 0 porotropy in continental structure has been discused by Robert Stoneley (Mon. Not. Roy. Astf. Soc., Geophysical Supplement, 5, No. 8, $3 \mathrm{a} ; 1949$ ). He finds that for near earthquakes, rrevesus values of the focal depth and thickness of ay ers might be found from the observations if the continental material had been thought to be isotropic. Further, for a transversely isotropic continent, $\mathrm{SH}$ waves would travel with a different velocity from that of $S V$, and the law of variation of velocity with direction would be different. With body waves, the sharp distinction into compressional and distortional waves would not hold, and an explosion would generate an $S$ wave as well as a $P$ wave ; an apparent difference in the instant of generation of $P$ and $S$ might arise. Stoneley has also proved that waves of the Rayleigh type can be propagated over the surface of a transversely isotropic body in which the axis of circular symmetry is normal to the free surface, supposed plane; in such waves the diminution of amplitude with depth is shown to be different from that in an isotropic body, so that the amplitudes of the surface waves generated by a source at a given depth will be different from that which they would be in an isotropic medium. Love waves can be propagated as in isotropic media. Byerly noted a possible double refraction effect on the crust of the earth for waves from the earthquake of July 6, 1934 (Bull. Seism. Soc. Amer., 28, $12 ; 1938$ ). Miss I. Lehmann may also have noted a similar effect ( $P u b$. Bur. Cent. Séism. Int., A, No. 12, 109 ; 1935).

\section{Bibliography of Seismology}

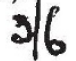

Vor, 14 . 3, of the Bibliography of Seismology frem the Dominion Observatory, Ottawa, has been chapiled by W. G. Milne (pp. 51-70. Ottawa: King's 